\title{
Tele-kiss.
}

\section{Nam-June Paik's expanded media in the light of Zen Buddhism}

\author{
KAMIL LIPIŃSKI \\ University of Bialystok
}

Abstract. Lipiński Karol, Tele-kiss. Nam-June Paik's expanded media in the light of Zen Buddhism. "Images" vol. XXVIII, no. 37. Poznań 2020. Adam Mickiewicz University Press. Pp. 308-316. ISSN 1731-450X. DOI 10.14746/i.2020.37.17

\begin{abstract}
The article offers a broad overview of Nam-June Paik's ideas of the expansion of video arts interpreted in the light of Zen Buddhism. His works recognized as the most significant examples of his marriage between the art theory and practice are marked by a thought-provoking vision of participatory culture, communicated in-between the networks in the post-industrial society. Our purpose is to reexamine his attitude to TV culture in the oscillation between Western and Eastern gaze considered in connection to the problems of emptiness and meditation drawn from Zen religious beliefs. In discussing his installations there is special stress to reconstruct his inner-insight into the subject of seeing and watching inscribed in a closed-circuit of the communication network.
\end{abstract}

KeYwords: Zen Buddhism participatory culture, TV culture, postindustrial society, meditation, emptiness

The work of art is valid if, and only if, it is aquiver with the sense of the future

André Breton

\section{Introduction}

Amidst the most thought-provoking artists working in the area of multimedia and video-art, Nam-June Paik reexamined the possibilities of the medium shifting emphasis to reconfigure the participatory, communicative experience seen through the lenses of Zen religious beliefs.

[1] H. Belting, Beyond iconoclasm. Nam-June Pail. Zen Gaze and the escape from representation, [in:] Iconoclash. Beyond the Image Wars in Science, Religion and Art, eds. B. Latour, P. Weibel, Karlsruhe, Cambridge, Massachussets 2002, p. 410.

[2] In Zen Buddhism "koan" is conceived as a particular exercise for mind which is based on paradoxical question or statement to introduce you to meditation.

[3] D. Joselit, Video and the Readymade, "October" 2007 , no. 11, p. 37.
Central to this activity, historically speaking, are the tools drawn from active participation to cross-fertilize old media into expanded forms related to the transmission of images in the distance in-between communication networks and "variations to a theme" of Zen Buddhism.[1] It is incredible to state that some of his predictions came true, such as the idea of sending images, video-telephones practically real for everyone, reading books beyond the libraries on their handy displays, not to mention the organization of video-conferences. Assuming certain aspects of separation and confronting time relations, Paik provided an in-depth insight into the specificity of the screen, the inner insight of the viewer, their mind, and the act of seeing. In Paik's view, time periods exists simultaneously more than linearly that can be comprehended in terms of dualistic nature of his video koan.[2] Bearing in mind the idea of reconnecting the participatory forms, Paik liberated "commercial TV's instrumentalized discourse”, employing socalled "dancing patterns".[3] The following four parts of this essay investigate how conceptual 
works brings together exchanges in-between media art and religion, as well as Western and Eastern cultures.. My aim is to argue for a more nuanced picture in which media-tricksterism and the space-shifting via electronic transmission of audiovisual content is seen not only as a product of a new zeitgeist but also as the result of profound meditation on the human condition.

\section{Towards Zen traces in conceptual works}

Before we proceed to expounding on Paik's views on electronic media, let us present those resulting from trhe intercultural relationship. Moving from Korea to Europe in the early 6os, Paik imbued his work with his indigenous culture and religionpromoted in his performances and video installations. These works, were marked by the strong interest in artificial intelligence, telecommunication networks, and new technology in the context of time-shifts. Beginning from 1956, when he came to West Germany to study music and philosophy, but after meeting Karlheinz Stockhausen and John Cage in Darmstadt in the late 1950s, Paik thoroughly investigated "Kant's Critique of Pure Reason, Hegel's Aesthetics and Zen Buddhism with textbooks on electronic circuity, physics, and indeterminacy theory".[4]

Undoubtedly, Korean-born artist was acquainted with the doctrine of Zen Buddhism.is even before his arrival to Europe making it inspiration for her works. As a result of conceptualizing experimental body methods combined with religious beliefs, Paik has rejoined "painting and its corporealization" [5] in the interpretation of the spare, poetic score of a La Monte Young composition: "draw a straight line and follow it". After accepting Karlheinz Stockhausen's invitation, Paik performed in Cologne on October 26,1961, in Zen for head, based on the action of dipping his head in paint and brushing his head across the rolling paper in parallel to Yves Klein's Anthropometries."[6] This technique has similarities in Asian calligraphy, providing an important insight into the Zen philosophy of mind to deepen the inner-na- ture of the human mind via art. This in-depth insight, viewed from the Buddhist perspective, spans Wisdom (prajna) as one of Triple Buddhist Triple Discipline, along with Morality (sila) and Mediation (Dhyna). More specifically, it represents intuitive knowledge, meaning "to fell in my own heart", or "to experience in my own mind", practically interpreted by Paik by employing calligraphic pattern of writing.

In line with the Fluxus movement, Paik conducted his experiments with the moving image by addressing the Zen Buddhism concept of emptiness. His expanded experimental movie Zen for Film (1964) was composed of a section of clean tape glued into a loop, inspired by John Cage's silent contemplation " $4 / 33$ ", and chance imagery filled with particles and scratches. In this particular work, "the light takes on the duration of the film which has given length in time. The film constrained the viewer to sit through it even when, in this case, there was nothing to be seen other than dust. The Zen gaze, in the case of the film, was not only expected but enforced - in a complete reversal of the standard cinema visit. The artist stages a photo by Peter Moore in which his body leaves a shadow on the empty screen during the film projection." [7] Making an explicit reference to Buddhism, it is important to stress that "a central Zen concept, emptiness (ku), is made artistically visible as an empty - white-ground of the picture, at the same time identical with the empty ground of being, and not only a reference to it." [8] What exists is a dynamic, self-oriented and self-knowing emptiness. The subconscious state is a state of self-capture of the Void. It is Emptiness itself in the aspect of self-knowledge, while art historians

[4] L. Koepnick, Framing Attention. Windows on modern Culture, Baltimore 2007, p. 200.

[5] G. Baker, The Artwork and its Tail, "October" 2001, vol. 97, p. 54.

[6] Ch. Zinman, The indeterminate origins of Digital Media Art, "October" 2018, no. 56, p. 18.

[7] H. Belting, op.cit., p. 401.

[8] H.G. Golinski, Paik on paper - die Sammlung Peter Wenzel im Museum Bochum, Bochum 2006, p. 11. 
would say that this work "fuse it with Minimalism's fascinations with the reduction of form." [9] In a parallel manner to Buddhist meditation:

[...] a film that showed nothing but a surface of light reflected by a screen. The film passing a loop for an indefinite period was enhanced in the long run by traces of scratches and other small deteriorations produced by the friction of the film in the projector returned by the screen. Typically, such incidents either go unperceived or demonstrate that the copy is of poor quality. Here, there are four clues or traces revealing the nature of the screen. Interference occurs in the present the televisual broadcast, they are not engraved on the film. The present becomes permanent, the work takes place in a time without return. These traces or faults of the produced image pose the screen as an object.[10]

In this passage, there is an explanation of the manifold interferences within the matter of an image, in which the time results from auteur's touch who decides on their level of expansion, as it changes every time it is projected, appearing seemingly "unique in their individual markings". [11] As a consequence of altering their play in its unique performance, this open-ended work, as Umberto Eco would argue, represents an open form of music through which listeners become actors.

Beginning from 1961, Paik started his studies in electronics. Together with Shuya Abe, he

[9] Ch. Zinman, The indeterminate origins..., p. 19. [10] J.-L. Beaudonnet, Des écrans singuliers, [in:] "Le cinéma, et après?", sous le direction de Maxime Schinfegel, Rennes 2010, p. 181.

[11] Ch. Zinman, The indeterminate origins..., p. 18.

[12] Yun M., Nam-June Paik. evolution, revolution, resolution, [in:] Nam-June Paik. Becoming Robot, ed. M. Chiu, M. Yun, New Haven, London 2015, p. 17.

[13] R.W. Kluszczyński, Film-video-multimedia. Sztuka ruchomego obrazu w erze elektronicznej, Warszawa 1999, p. 81.

[14] Herzogenrath W., Wschodnio-zachodni nomada w zaciszu globalnej sieci, [w:] Widok, Driving Media, ed. A. Kubicka-Dzieduszycka, K. Dobrowolski, Wrocław 2009, p. 43.

[15] L. Movin, The Zen master of video Nam June Paik: Between minimalism and overkill, prepared a program to broadcast a single vertical line to Participation TV (1963), to enable the viewers to create and control graphic patterns on a television screen by using a microphone and a foot-operated switch.[12] Furthermore, this voice-generated content amplified the acoustic signals to the monitor evokes an explosion of connected lines. To put it differently, "the recipient could create and transform images and television programs." [13] Along with cooperating with the young electro-engineer Shuya Abe and Hideo Ichida, an avant-garde electrician who specialized in electromagnets, Paik researched the behavior of electrons in television-sets. The duet Abe and Paik constructed the robot K-456 (1963-1964), measuring $160 \mathrm{~cm}$, the name of which stems from Wolfgang Amadeus Mozart's piano concerti (Kochel number 456). They transferred some of their elements for a life-size robot activated by the twenty-channel remote-control. Moreover, the robot walked on its legs, which was quite troublesome for the two-legged robot. As a machine with its digestive system, the robot was able both to make sounds using a special device and to scatter white beans around him. The robot quoted from the speeches of John F. Kennedy, as well as from those of Churchill and Hitler. With its public debut in August 1964 at the second New York Festival of the Avant-Garde in Judson Hall, the first performance of the robot took place in Wuppertal during the 24 Stunden in 1965. In 1976, the robot was no longer able to stand upright and was housed in a crate.[14] The construction was shown in Berlin, Sweden and London, "ending its 'tour' in 1982 during the performancec. It was then restored in 1982 on a walk along Madison Avenue in front of Whitney of American Art in New York, triggering the "First Accident of the 21st Century". During this performance, Paik was run over by a car driven by the artist William Anastasi at the intersection of $75^{\text {th }}$ street and Madison Avenue. Subsequently he was brought back to the Whitney Museum of American Art during a major retrospective exhibition there".[15] It is difficult to recall all 
the interpretations of this this encounter, nevertheless one of the possible explanations is that it reflects "potential problems that arise when technologies collide out of human control".[16]

Let us briefly mention that Paik pursued an interactive deconstruction of video image by employing electromagnetically-distorted images of Magnet TV (1965). With an emphasis to explore electronics and the power of magnetic field, Paik constructed a "Demagnetizer", or Life Ring (1965) mirroring the participant's impact in order to distort the television image. Based on the circular electromagnet, one could alter wave pattern of video screen evoking an active circuit of electro waves. In discussing his experimental input to TV sets Korean-born artist argued that "the purpose of television is emptiness - the apparatus seems to be "buddhist's machine".[17] In the cooperation with Shuya Abe Paik invented Video Synthesizer (19691970) which was making endless variations of vibrantly colored forms in his videotapes "modified, hijacked and crushed".[18] The reason why video synthesizer was considered as a very special tool was the fact that an "apparatus allowed a controlled manipulation of the previously rather uncontrollable electronic image." [19] In brief, TV assemblages both demonstrate connection and a close relationship in-between the spectator and the flickering images reflecting viewers' movement. Put simplythis participatory mechanism aimed totransform a passive TV set into a creative tool responding to the spectator's movements.

\section{Tele-kiss, or a video message from a distance}

Elsewhere, I intended to analyze this concept of interactivity, but here let me deal in further detail with the ideas of global broadband communication across cultures in "Global Groove" (1973), produced at the WNET TV Lab with John Godfrey and first broadcast in January, 1974. In briefly discussing its genesis, let us mention that "Global Groove was actually a government commission from the USA to promote international understanding requested in the year 1971 when the Vietnam War had still not come to an end. Both visually and acoustically, Paik strung together 21 sequences from different cultural areas, including both high and popular culture: two go-go dances appear, a Navajao Indian signs and play drums, Korean dances are performed, a black African is seen fist-fighting, and a Japanese commercial for Pepsi-Cola flashes by." [20] In this single-channel videotape, the juxtaposition of Allen Ginsberg's chanting in the East Village with Korean dancers may suggest the complexity of the world while, and to the contrary, Pepsi commercials in Japanese symbolized the unification of the media world within McLuhan's "global village". By the same token, Paik introduced the "dancing pattern" as a concept based on the underlying premise that "network is commodity (broadcast TV) meaning that "there is no difference in the "electrons and protons" that constitute the one and the other." [21] Before the advent of the internet, Paik pointed out the possibility of sharing artworks, a vision of a common network of information where everyone can present works, events or any kind of information to any possible recipient who may understand it. To explain the distribution system, I will take another quotation form Paik's article, in which these points are well-illustrated: "Marx gave much thought to the dialectics of the production and the production medium. He had thought rather simply that if the workers (producers)

[in:] Nam-June Paik Video Sculptures: Electronic Undercurrents, Copenhagen 1996, p. 30-31.

[16] E. Kac, Foundation and development of robotic art, "Art Journal" 1997, vol. 56, no. 3, p. 62.

[17] D. Mersch, Teorie mediów, przeł. E. Krauss, Warszawa 2010, p. 8o.

[18] Ch. Zinman, Nam-June Paik's Etude 1 and the indeterminate Origins of Diginal_Art, "October" 2008, no. 164, p. 21.

[19] Ibidem, p. 213.

[20] S. Martin, Global Groove, [in:] Video Art, ed. U. Grosenick, Cologne 2006, p. 78.

[21] D. Joselit, No exit video and the ready made, "October" 2007, no. 119, p. 43. 


\section{2}

VARIA

owned the production's medium, everything would be fine. He did not give creative room to the DISTRIBUTION system. The problem of the art world in the ' 60 s and ' 70 s is that although "the artist owns the production's medium, such as paint or brush, even sometimes a printing press, they are excluded from the highly centralized DISTRIBUTION system of the artworld." [22] In line with abandoning live performances in the 1980s, Paik turned to massive, multi-monitor video constructions, such as Goodbye Mr. Orwell (1984), inspired by Daniel Bell's idea of postindustrial society and the famous futurological dystopian book written by George Orwell under the title "1984". With an eye toreconnect Paris and New York broadcast program coordinated live transmission from around the world. Long before the advent of Vj's practice, Paik produced live show performances $6000 \mathrm{~km}$ distant from the United States and Europe with live images of twelve artists, including the images of dancing choreographer Merce Cunningham, the composers John Cage and Philip Glass, the painter Robert Combas. This "happening video", divided into two groups (one in $\mathrm{FR}_{3}$ studio in Paris and the second in WNET TV in New York), was recorded by seven cameras in one place, along with mixing tables, which made it possible to connect through satellite in one broadcast, divided into four parts. What was innovative in this global interaction was that they employed complex designs to implement interactive performance. Inspired by Paik's work, Jean Paul Fargier argued that, "thanks to the satellite, the mysteries

[22] O.F. Smith, Fluxus praxis: an exploration of connections, creativity, and community, [in:] At a Distance. Precursors to Art and Activism on the Internet, Cambridge, London 2005, p. 131. From: Nam June Paik, George Maciunas and Fluxus, „Flesh Art” 1978, nos. 84-85, p. 48.

[23] J.-P. Fargier, Ma mère Paik, "Art Press" 1989, no. 141, p. 25.

[24] R. Hoskote, N. Adajania, NJP. Contributions to an artistic Anthropology. p. 17, <https://njpacen.ggcf.kr/>.

[25] Ibidem. of meetings with others (fortuitous encounters) will accumulate by geometric progression and should become the main real estate product of post-industrial society." [23]

In a similar vein, Paik was hired as a consultant by Howard Klein, Director of the Rockefeller Foundation, where he created the Electronic Superhighway (1984). This was arranged in a multi-channel room-sized installation bringing together Los Angeles and New York with the purpose of transmitting media images, as a reference to the "superhighways" unifying the country by road in U.S. in the 1950s. This fifty-one channel sculpture was also organized in Venice Biennale (1993), linking the Italian organization with Ulan Bator. This two-way satellite called "ninja" foreshadowed the idea of connecting to everyday experiences and multi-faced communication with manifold video transfigurations. Among multiple ideas that were supposed to make video broadcasting possible, Paik introduced the concept of the "tele-kiss", as a electronic form of human communication to send images to each other via video images. In explaining Paik's form of shape-shifting in the light of Buddhist beliefs, it can be argued that he attempted to surpass the distant polarity between two separate venues, as there is "no center or periphery, no subject or object, no technology or nature [...] and the widening rifts between individuals and communities in transitional communities - suggests a specific position from within the Buddhist philosophical spectrum towards the dogma of polarity. [24] To put it differently, in Buddhism "the fundamental doctrine of the Yogachara is that of chitta-matra, or "mind-only", meaning that since reality is apprehensible only through the mind, and all experience is made possible only by the mind, it is by purifying the mind rigorously of all polarities." [25] Paik had clearly shown that a window into the spectatorial inner world can be apprehended via different means of sights of seeing, With an emphasis on the multiplication of the frames in different contexts Paik combined linear time relations advocating a rapid change of telecommunica- 
tion. This way, he tossed the bridge between the places all around the world despite the distance. in the real-time audiovisual performances involving a diverse group of avant-garde artists.

\section{Between closed-circuit "emptiness" and meditation}

Emptiness is also central to the most important triptych in Nam June Paik's works. Together with the idea of meditation, they will be more fully illustrated by the following artwork exhibited in 2008 in Staatliche Museen zu Berlin, Nationalgallerie 2008 under the title "Triangle. Video Buddha and Video Thinker” (1978/1991). This triptych presents on one edge the sculpture of a sitting Buddha looking at a television set while the camera registers its image and transmits it to the screen viewed by the Buddha. This work may signalize the connection between Buddhism, meditation and television. This artwork recalls the most significant element in Paik's signature installation, TV Buddha [1974], with a bronze statue of a sitting Buddha within a closed-circuit television monitor. Convincingly, Hans Belting noted that "there is a striking analogy between Zen for TV and the TV Buddha, although the two works seem to do the opposite, the one emptying the TV imagery by contracting it to an abstract line and the other producing images all the time, albeit via the same, repeated image." [26] In this sculpture, in this exposition, a camera registers the statue of the Buddha, who sits contemplating the image of himself on a monitor linked to the camera. In reconstructing the viewer's position, Belting also argued that "There is actually no viewer but a Buddha statue, and we are seeing what the statue cannot see the duplication of the same image which thereby empties himself. The statue is also an image which means that an image is mirrored in an image." [27] Viewed from the Buddhist perspective, a statue sitting during Zen meditation (zazen) is perceived as mental composure and contemplation, which leads to "[achieving] satori - the Japenese word for the experience of enlightenment, that is "self-intuition": What is meant is the "opening of the spiritual eye", the "awakening to one's own true essence" and thus to the essence of all existence." [28] More specifically, D.T. Suzuki maintains: "To experience Satori is to become conscious of the Unconscious (mushin, nomind)...Art has always something of the Unconcious about it." [29] What is a crucial aspect for this Buddha's gaze is that "zen meditation uses repetitive phrases in meditation to lead to "higher levels of consciousness." [30]. Let us discuss this issue more profoundly. In Teng's view, "first of all, it is necessary to practice meditation by quietly sitting cross-legged. When this exercise is fully mastered, Prajna (intuitive knowledge) grows out of it, and by virtue of this Prajna, the seeing into one's self-nature is attained.' [31] Following this line of thought, it is important to note that the Buddha's position, interpreted in terms of Zen doctrine, can be seen as "meditation (dhjana) is not attributed to any particular form of action, e.g. staying silent and still in a cross-legged position. Rather, it means a state of mind orientation to capture its own nature, the emptiness that guides it, regardless of what activities are performed. It is achieved when its practice is not assumed, so spontaneously." [32] What is more, it can be argued that a Buddha gazing at the screen raises the problems of video koan. To quote further from D.T. Suzuki: "In Zen, a koan is a statement formulated in a confusing, alogical manner of expression, indicating an 'ultimate truth'[33]. Here it should be remarked that "koans cannot be resolved by means of logical thought, but rather only by awakening a deeper level of the mind beyond the discursive intellect." The

[26] H. Belting, op.cit., p. 402.

[27] Ibidem.

[28] H.G. Golinski, op.cit., p. 11.

[29] D.T. Suzuki, Zen and Japanese Culture,

Princeton 1970, p. 220.

[30] Ibidem, p. 190.

[31] Ibidem, p. 27.

[32] K. Kosior, Szpik zenu. D.T. Suzuki o podświadomości (nie-umyśle), [in:] Odkrywanie dharmy, red. K. Kosior, Lublin 1993, p. 73.

[33] H.G. Golinski, op.cit., p. 11. 
koan can be seen in the Buddha staring at a live image of himself and the replay of a videotaped representation. What seems to be convincing is that "the goal of this meditation was an absolute emptiness, beyond time and space," but the Buddha would see his body and therefore be "forced to become a modern Narcissus." [34]

In watching TV cross-legged, Buddha, as D.T. Suzuki pointed out, may suggest that "the seeing is not reflecting on an object as if the seer had nothing to do with it. The seeing, on the contrary, brings the seer and the object seen together, not in mere identification but the becoming conscious of itself, or rather of its working." [35]. To elaborate on the problem of the sight, let us mention that "the seeing (chien is also called recognizing or understanding, or, better, experiencing (wu in Chinese and satori in Japanese). The character $\mathrm{Wu}$ is composed of "heart" (or "mind")." [36] There is more to the claim that the Buddha's gaze may represent "dhyana", understood as "to see inwardly the immovability of one's self nature-this is chan (dhyana)... Outwardly, to be free from the notion of form-this is chan. Inwardly, not to be disturbed-this is ting (dhyana).[37] This specific calmness, an image of the freed-mind posture, defines that separate time of the personified Buddhist viewer, suggesting that the fixed time of an image introduced in a constant loop points to two separate orders. There is a coincidence of two times: the present time and the past time restored. There is more to elaborate on. Drawing parallels between Western and Eastern civilization, on the second edge of the installation there was a statue of the Thinker by Auguste Rodin (Le penseur) in a state of reflection in front of the TV screen. "The title TV Rodin taken literally identifies the Thinker with Rodin much as Rodin has identified the

[34] H. Belting, op.cit. p. 402.

[35] D.T. Suzuki, op.cit., p. 25-26.

[36] Ibidem.

[37] Ibidem, s. 33.

[38] H. Belting, op.cit. p. 413.

[39] Ibidem, p. 28.

[40] Ibidem. figure with the visionary Dante and introduced it as a veiled self-portrait of the artist." [38] Rodin's posture resembles the Western type of contemplation of a person having some deep thoughts. In Suzuki's view, when "seeing into one's self-nature", this seeing also has a binding effect on us if it is constructed as having something in it specifically set up; that is, if the seeing is a specific state of consciousness, for this is the "binding." [39] This contemplative posture in Rodin's sculpture may be interpreted as insight into the self-nature of closed-circuit TV. The comparison of the meditation mode of Zen, conceived as Dhyana when it is viewed, and the 'couch potato' image of the TV consumer may suggest meditation and emptiness from the Eastern part and the contemplative mode of observing beauty in Western vision. Conflating the viewing experience with meditation the Rodin's statue represents the self-reflexivity of the television spectator's experience. Finally, on the third corner, there are two TV monitors oriented to each other; the TV screens present, on one the hand, the face of Buddha and, on other hand, the vision of Rodin's statue, facing each other in a comparable situation. The dualistic relationship provides an inner insight composed of two opposing screens, suggesting the division in Buddhist Zen "into a duality... the object and the shadow." [40] These two opposing narcissistic images may represent the mirroring face to one another, where there is no human anymore, just the dialogue of the TV sets, suggesting a dehumanization in which every experience is mediated to the extent that we live only for ourselves in a matrix of channels and cables, where nobody knows where are the beginning and end. What is more, by intervening from the outside, the sojourner might respond by leaping into action and placing a hand over the camera lens. This participatory gesture accentuates the difference between a live connection registered by a camera and a prerecorded tape reliant upon the closed circuit of interfaces set to trigger the mirror reflection in both TV monitors. It is, however, difficult to state which one of this processual unities of "dhyana and 
prajna" is more accurate in this installation, as "the first is staring, the second is seeing and both of them are inseparable. The effect of meditation - knowledge." [41] From these passages, I hope we gain a glimpse into some aspects of Zen thought as promulgated by D.T. Suzuki. The comparison of these postures represents "two very different cultures - the old Buddhist religion and worldwide TV communication. It is, however, precisely this overwhelming contrast which Paik collapse." [42] The core of this installation in both cases is the seeing into one's inner being, known as self-nature, widespread in both Western thought and Eastern reflection, two forces facing each other and reflecting their mirroring screens.

\section{Concluding remarks}

In conclusion, let me offer a few brief reflections on Nam-June Paik's expansion of video-screen media and the telecommunication network. His marriage of theory with practice provided an insight into the inner nature of culture, kept up to date and looking ahead to the future alongside the development of civilization. Paik providess an introspective, anthropomorphic vision of humanity entangled in expanded forms perfected by late-twentieth-century electronics to transform ancient archetypes into modern forms of media-tricksters, including, in his late period, lasers "transmitted across infinite space." [43] His works progressed steadily through 1970, expanding in scale from one piece to an international project linking various continents, keeping the public aware of the possibility of sending images within one information network before the advent of the internet. Seeking an innovative study of the interaction between the anthropomorphized robots symbolizing the media shift towards artificial intelligence may lead to a modern way of thinking about cultivating tradition, "for otherwise there will be no chance of even a glimpse into the secrets of Zen experience." [44] Paik's overreaching and innovative aim was to situate Zen theology within a larger vision of contemporary art and the culture, bridging national boundaries. Kore- an-born artist rightly focuses on a TV set as the key to understanding the everyday use of media by addressing it via meditation and emptiness in the context of various images as expressed in the doctrine of Zen. Bearing in mind making the most difficult cultural metaphors accessible to every media user, Paik spread prognostic ideas ahead of their time. Paik illustrate these themes by a careful analysis of post-industrial society and a major strenght of his works is their discussion on the ways how they reflect human beings in the new shifting world. A common form of this circular, meditative relationship is an interplay between timelines, as - "thanks to technology. we can live not only in the future but also in the past. "We have to go back and forth"; reliving history will be "an important content" for the new software[45].

\section{B I B L I O G R A P H Y}

Baker G., The Artwork and its Tail, "October" 2001, vol. 97

Beaudonnet J.-L., Des écrans singuliers, [in:] "Le cinéma, et après?", sous le direction de Maxime Schinfegel, Rennes 2010

Belting H., Beyond iconoclasm. Nam-June Pail. Zen Gaze and the escape from representation, [in:] Iconoclash. Beyond the Image Wars in Science, Religion and Art, eds. B. Latour, P. Weibel, Karlsruhe, Cambridge, Massachussets 2002

Fargier J.-P., Ma mère Paik, "Art Press" 1989, no. 141

Golinski H.G., Paik on paper - die Sammlung Peter Wenzel im Museum Bochum, Bochum, p. 11

Herzogenrath W., Wschodnio-zachodni nomada $w$ zaciszu globalnej sieci, [w:] Widok, Driving Media, ed. A. Kubicka-Dzieduszycka, K. Dobrowolski, Wroclaw 2009

Hoskote R., Adajania N., NJP. Contributions to an artistic Anthropology, <https://njpac-en.ggcf.kr/>

Joselit D., No exit video and the ready made, "October" 2007, no. 119

Joselit D., Video and the Readymade, "October" 2007, no. 11

[41] K. Kosior, op.cit., p. 73.

[42] H. Belting, op.cit. p. 404.

[43] M. Kemp, Lancing Lasers, "Nature" 2000, vol. 404, 6 April, p. 546.

[44] D.T. Suzuki, op.cit., p. 59.

[45] Ibidem. 
Kac E., Foundation and development of robotic art, "Art Journal" 1997, vol. 56, no. 3

Kemp M., Lancing Lasers, "Nature" 2000, vol. 404, 6 April

Kluszczyński R.W., Film-video-multimedia. Sztuka ruchomego obrazu w erze elektronicznej, Warszawa 1999

Koepnick L., Framing Attention. Windows on modern Culture, Baltimore 2007

Kosior K., Szpik Zenu. D.T. Suzuki o podświadomości (nie-umyśle), [in:] Odkrywanie dharmy, red. K. Kosior, Lublin 1993

Martin S., Global Groove, [in:] Video Art, ed. U. Grosenick, Cologne 2006

Mersch D., Teorie mediów, przeł. E. Krauss, Warszawa 2010

Movin L., The Zen master of video Nam June Paik: Between minimalism and overkill, [in:] Nam-June Paik
Video Sculptures: Electronic Undercurrents, Copenhagen 1996

Paik N.J., George Maciunas and Fluxus, "Flesh Art", 1978, nos. 84-85

Smith O.F., Fluxus praxis: an exploration of connections, creativity, and community, [in:] At a Distance. Precursors to Art and Activism on the Internet, Cambridge, London 2005

Suzuki D.T., Zen and Japanese Culture, Princeton 1970

Yun M., Nam-June Paik. evolution, revolution, resolution [in:] Nam-June Paik. Becoming Robot, ed. M. Chiu, M. Yun, New Haven, London 2015

Zinman Ch., Nam-June Paik's Etude 1 and the indeterminate Origins of Diginal Art, "October" 2008, no. 164

Zinman Ch., The indeterminate origins of Digital Media Art, "October" 2018, no. 56

Acknowledgments: The analysis of the exhibition in Berlin was possible thanks to the study trip organized by Grzegorz Dziamski, Jacek Zydorowicz and Marta Kosińska. 